\title{
Significant narrowing of the circumflex artery leads to worse outcomes than right coronary artery narrowing in patients with anterior myocardial infarction treated invasively
}

\author{
M. Kozuch • P. Kralisz • M. Rog-Makal • \\ H. Bachorzewska-Gajewska $\cdot$ S. Dobrzycki
}

Published online: 28 March 2015

(C) The Author(s) 2015. This article is published with open access at Springerlink.com

\begin{abstract}
Background Occlusion of the circumflex artery $(\mathrm{Cx})$ often does not present signs in the ECG. It can lead to delayed angiography during ST-elevation myocardial infarction (STEMI). The aim of this analysis was to determine if $\mathrm{Cx}$ narrowing is related to diverse outcomes in comparison with right coronary artery (RCA) stenosis in patients with STEMI, treated with percutaneous coronary intervention (PCI) of the left descending artery (LAD).

Methods and results Inclusion criteria were as follows: first STEMI treated with PCI of the LAD and additional significant $(\geq 70 \%) \mathrm{Cx}$ or RCA narrowing - two-vessel disease. A total of 234 consecutive patients with STEMI were included. Total mortality was estimated during long-term follow-up, at mean $639( \pm 224)$ days after STEMI. Patients with $\mathrm{Cx}$ narrowing constituted $46 \%(N=108)$ of the study population, and patients with RCA narrowing amounted to $54 \%(N=126)$. Patients with narrowing of the $\mathrm{Cx}$ had worse long-term outcomes in terms of mortality than patients with RCA narrowing ( 22 vs. $11 \%, p<0.05$, respectively). Multiple regression analysis showed independent risk factors for death during long-term follow-up such as: age, ejection fraction and Cx narrowing.

Conclusion Significant Cx narrowing leads to worse outcomes than RCA narrowing in patients with STEMI treated with PCI of the LAD.
\end{abstract}

Keywords Myocardial infarction - Revascularisation · Mortality $\cdot$ Prognosis

\section{Introduction}

Over the past decades, the outcomes in patients with ST-elevation myocardial infarction (STEMI) have improved [1]. However, putting aside good early results, late outcomes are still not satisfactory, especially in patients with non-STelevation acute coronary syndromes in whom late prognosis is worse than in STEMI patients. Thus, searching for predictors of long-term mortality is still justified. Location of infarction is established as one such predictor. Inferior wall STEMI is thought to have a better long-term prognosis than anterior STEMI [2]. However, inferior STEMI may be the result of either circumflex artery $(\mathrm{Cx})$ or right coronary artery (RCA) disease, leading to different outcomes. Nevertheless, significant narrowing of the $\mathrm{Cx}$ frequently does not present with ischemic signs on the ECG, even if the artery is occluded. Such a phenomenon can lead to the wrong qualification and delayed angiography during STEMI or stable coronary artery disease [3]. Hence, inadequate treatment of the narrowing of this artery can lead to worse outcomes. The number of arteries affected by atherosclerosis is an additional factor influencing the outcome. Moreover, prognosis may be affected by coronary artery dominance. It has been reported that left coronary artery dominance in the case of significant coronary artery disease is related to worse prognosis [4]. Moreover, the issue whether Cx or RCA disease is worse, still remains unclear. Additionally, different outcomes related to $\mathrm{Cx}$ or RCA stenosis in patients with anterior STEMI treated invasively have not been confirmed. Accordingly, the aim of this analysis was to establish if narrowing of the $\mathrm{Cx}$ is related to diverse outcomes in com- 
parison with the narrowing of RCA in patients with STEMI treated with percutaneous coronary intervention (PCI) of the left anterior descending artery (LAD).

\section{Methods}

The study was conducted among consecutive STEMI patients who underwent PCI of the LAD in our centre between 2005 and 2011. The study was based upon retrospective analysis of a clinical registry conducted in the authors' own department. Inclusion criteria were as follows: first STEMI treated with PCI of LAD and additional, visually estimated, significant ( $\geq 70 \%$ ) narrowing of the $\mathrm{Cx}$ (segments 11-13) or RCA (segments 1-3) - two-vessel disease. Patients with ostial Cx stenosis or total occlusions of the $\mathrm{Cx}$ or RCA were excluded. Inclusion criteria were met by 234 patients who constituted a homogenous group. Every significant narrowing was treated invasively with planned, staged PCI. Staged PCI was performed within the first month after STEMI in patients with persisting clinical symptoms and/or a large vascularisation area of the narrowed vessel, according to the regimen prevailing in the centre. Patients with unsuccessful planned PCI were excluded from the analysis. Pharmacotherapy was administered according to the European Society of Cardiology guidelines binding at that time. All patients received a loading dose of clopidogrel $(600 \mathrm{mg})$ and aspirin (300 mg). There were no differences concerning other pharmacological agents between the compared groups of patients. Mean follow-up was $639( \pm 224)$ days. Total mortality was estimated at follow-up. Informed consent was obtained from each patient.

\section{Follow-up}

Follow-up consisted of three stages. The first stage was a questionnaire sent to patients 2 years after myocardial infarction. The next stage, if the patient did not send the questionnaire back, was telephone contact with the patient or with his family. Missing data were collected from the Provincial Administration Office. Information concerning endpoint was obtained in $100 \%$ of the cases. The office provides information concerning death of a person; however, the cause of death remains unknown. The study was approved by the local Bioethics Committee.

\section{Statistical analysis}

Distribution of variables was assessed with the Kolmogorov-Smirnov test followed by the Student's $t$-test, ANOVA test, or Mann-Whitney test for comparative analysis, the choice of a test depended on the distribution of a variable. The interdependences between constant variables were calculated with the Spearman or Pearson test depending on the statistical distribution. Correlations between dichotomous variables were analysed with the chi-square test. Multivariable analysis was performed with logistic regression testing. A $P$ value $<0.05$ was considered statistically significant. The results are presented as mean values with standard deviation or as percentage values presenting relative frequency. Statistical analysis was performed with Statistica 10.0 program (StatSoft, Inc. Tulsa, USA).

\section{Results}

The study population was composed of $46 \%(N=108)$ of patients with $\mathrm{Cx}$ narrowing and $54 \%(N=126)$ with RCA narrowing. The $\mathrm{Cx}$ and RCA groups did not differ according to baseline clinical data (Table 1). There were no significant differences concerning either biochemical or history data (Table 2). Pharmacological treatment possibly affect-

Table 1 Baseline clinical and angiographic characteristics

\begin{tabular}{|c|c|c|c|c|c|}
\hline & \multicolumn{2}{|c|}{$\begin{array}{l}\text { RCA group } \\
(N=126)\end{array}$} & \multicolumn{2}{|c|}{$\begin{array}{l}\text { Cx group } \\
(N=108)\end{array}$} & \multirow[t]{2}{*}{$p$} \\
\hline & $\begin{array}{l}\text { Mean } \\
\text { or } N\end{array}$ & $\begin{array}{l}\text { SD or } \\
\%\end{array}$ & $\begin{array}{l}\text { Mean } \\
\text { or } N\end{array}$ & $\begin{array}{l}\text { SD or } \\
\%\end{array}$ & \\
\hline Age (years) & 64.92 & 9.92 & 66.30 & 12.44 & ns \\
\hline Male gender & 91 & $72 \%$ & 74 & $69 \%$ & ns \\
\hline Body mass index $(\mathrm{kg} / \mathrm{m} 2)$ & 28.10 & 5.45 & 26.65 & 3.09 & ns \\
\hline $\begin{array}{l}\text { Systolic blood pressure } \\
\text { on admission }(\mathrm{mmHg})\end{array}$ & 153.71 & 145.54 & 146.60 & 36.11 & ns \\
\hline $\begin{array}{l}\text { Diastolic blood pressure } \\
\text { on admission }(\mathrm{mmHg})\end{array}$ & 85.81 & 14.09 & 90.12 & 17.50 & ns \\
\hline $\begin{array}{l}\text { Heart rate on admission } \\
\text { (beats/minute) }\end{array}$ & 75.23 & 16.27 & 78.80 & 16.86 & ns \\
\hline $\begin{array}{l}\text { Ejection fraction of left } \\
\text { ventricle }(\%)\end{array}$ & 40 & 10.44 & 42 & 10.32 & ns \\
\hline $\begin{array}{l}\text { Mean Killip class on } \\
\text { admission }\end{array}$ & 1.42 & 0.51 & 1.46 & 0.54 & ns \\
\hline $\begin{array}{l}\text { Time pain to door } \\
\text { (minutes) }\end{array}$ & 267.45 & 187.23 & 248.49 & 174.12 & ns \\
\hline $\begin{array}{l}\text { Mean number of im- } \\
\text { planted stents }\end{array}$ & 1.27 & 0.70 & 1.21 & 0.51 & ns \\
\hline $\begin{array}{l}\text { POBA during index } \\
\text { procedure }\end{array}$ & 3 & $2 \%$ & 3 & $3 \%$ & ns \\
\hline $\begin{array}{l}\% \text { of implanted DES dur- } \\
\text { ing index procedure }\end{array}$ & 40 & $32 \%$ & 36 & $34 \%$ & ns \\
\hline $\begin{array}{l}\text { POBA during second } \\
\text { stage of PCI }\end{array}$ & 0 & $0 \%$ & 1 & $1 \%$ & ns \\
\hline $\begin{array}{l}\% \text { of implanted DES dur- } \\
\text { ing second stage of PCI }\end{array}$ & 41 & $33 \%$ & 39 & $36 \%$ & ns \\
\hline $\begin{array}{l}\text { PCI of proximal LAD } \\
\text { during index procedure }\end{array}$ & 52 & $41 \%$ & 42 & $39 \%$ & ns \\
\hline RCA dominance & 82 & $65 \%$ & 72 & $67 \%$ & ns \\
\hline
\end{tabular}

$R C A$ right coronary artery, $C x$ circumflex artery, $n s$ not significant, $L A D$ left descending artery, $D E S$ drug-eluting stent, $P O B A$ plain old balloon angioplasty, $P C I$ percutaneous coronary intervention, $S D$ standard deviation 
Table 2 Baseline biochemical and history characteristics

\begin{tabular}{|c|c|c|c|c|c|}
\hline & \multicolumn{2}{|c|}{$\begin{array}{l}\text { RCA group } \\
(N=126)\end{array}$} & \multicolumn{2}{|c|}{$\begin{array}{l}\text { Cx group } \\
(N=108)\end{array}$} & \multirow[t]{2}{*}{$p$} \\
\hline & $\begin{array}{l}\text { Mean } \\
\text { or } N\end{array}$ & $\begin{array}{l}\text { SD or } \\
\%\end{array}$ & $\begin{array}{l}\text { Mean } \\
\text { or } N \\
\end{array}$ & $\begin{array}{l}\text { SD or } \\
\%\end{array}$ & \\
\hline $\begin{array}{l}\text { Creatinine on admission } \\
(\mathrm{mg} / \mathrm{dl})\end{array}$ & 1.01 & 0.22 & 1.06 & 0.19 & $\mathrm{~ns}$ \\
\hline $\begin{array}{l}\text { Total cholesterol on } \\
\text { admission }(\mathrm{mg} \%)\end{array}$ & 178.87 & 54.17 & 193.64 & 44.13 & ns \\
\hline $\begin{array}{l}\text { HDL cholesterol on } \\
\text { admission }\left(\mathrm{mg}^{2} \%\right)\end{array}$ & 44.06 & 14.91 & 47.66 & 10.09 & ns \\
\hline $\begin{array}{l}\text { LDL cholesterol on ad- } \\
\text { mission }(\mathrm{mg} \%)\end{array}$ & 110.00 & 40.43 & 114.79 & 45.83 & ns \\
\hline $\begin{array}{l}\text { Triglycerides on admis- } \\
\text { sion }(\mathrm{mg} \%)\end{array}$ & 116.92 & 60.65 & 127.32 & 58.16 & ns \\
\hline $\begin{array}{l}\text { Glucose level on admis- } \\
\text { sion }(\mathrm{mg} \%)\end{array}$ & 119.38 & 33.72 & 115.50 & 43.92 & ns \\
\hline CKMB on admission (IU) & 73.39 & 79.93 & 103.48 & 138.16 & $\mathrm{~ns}$ \\
\hline Maximal CKMB (IU) & 250.68 & 245.34 & 253.35 & 331.97 & ns \\
\hline Hypercholesterolaemia & 59 & $47 \%$ & 54 & $50 \%$ & ns \\
\hline $\begin{array}{l}\text { History of diabetes } \\
\text { mellitus }\end{array}$ & 25 & $20 \%$ & 20 & $19 \%$ & ns \\
\hline History of hypertension & 73 & $58 \%$ & 62 & $57 \%$ & ns \\
\hline
\end{tabular}

$R C A$ right coronary artery, $C x$ circumflex artery, $n s$ not significant, $H D L$ high-density lipoprotein cholesterol, $L D L$ low-density lipoprotein cholesterol, $C K M B$ creatine kinase-myocardial band, $S D$ standard deviation

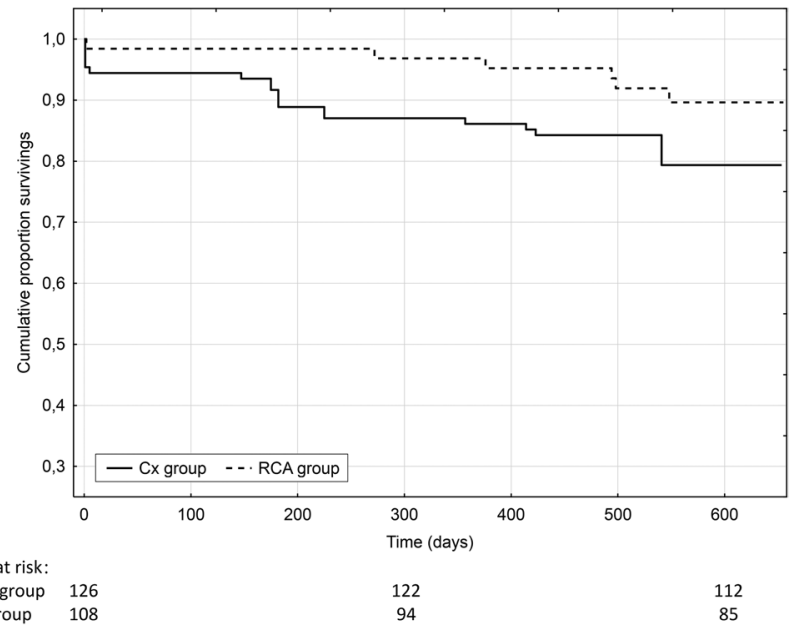

Fig. 1 Kaplan-Meier curves displaying cumulative proportion survivals during long-term follow-up according to circumflex or right coronary artery narrowing $(p<0.05)$

ing the outcome (beta-blockers, ACE inhibitors and statins) was also comparable at discharge. Long-term mortality was estimated at a level of $16 \%$. Mortality was higher in patients with $\mathrm{Cx}$ than with RCA narrowing $(22(N=23)$ vs. $11 \%(N=14)$ respectively, $p=0.031$, (Fig. 1$)$. The ejection fraction of the left ventricle, age, glycaemia on admission, significant $\mathrm{Cx}$ stenosis and creatine kinase-myocardial band on admission were found to be risk factors for long-term mortality in univariate analysis (Table 3 ). Multiple regres-
Table 3 Significant risk factors for long-term mortality in univariate analysis

\begin{tabular}{|c|c|c|c|c|c|}
\hline & \multicolumn{2}{|c|}{$\begin{array}{l}\text { Alive } \\
(N=197)\end{array}$} & \multicolumn{2}{|c|}{ Death $(N=37)$} & \multirow[t]{2}{*}{$p$} \\
\hline & $\begin{array}{l}\text { Mean } \\
\text { or } N\end{array}$ & $\begin{array}{l}\text { SD or } \\
\%\end{array}$ & $\begin{array}{l}\text { Mean } \\
\text { or } N\end{array}$ & $\begin{array}{l}\text { SD or } \\
\%\end{array}$ & \\
\hline $\begin{array}{l}\text { Ejection fraction of left } \\
\text { ventricle }(\%)\end{array}$ & 42.88 & 9,37 & 26.55 & 6.97 & $<0.001$ \\
\hline Age (years) & 64.14 & 10.60 & 72.80 & 8.24 & $<0.001$ \\
\hline $\begin{array}{l}\text { Glucose level on ad- } \\
\text { mission (mg \%) }\end{array}$ & 112.89 & 29.68 & 150.25 & 61.52 & 0.005 \\
\hline Significant Cx stenosis & 84 & $43 \%$ & 23 & $63 \%$ & 0.021 \\
\hline CKMB on admission & 78.83 & 83.66 & 130.62 & 160.88 & 0.013 \\
\hline
\end{tabular}

Table 4 Risk factors of death during the follow-up in multiple regression analysis

\begin{tabular}{lllllll}
\hline & $\beta$ & $\begin{array}{l}\text { SE } \\
\text { of } \beta\end{array}$ & B & $\begin{array}{l}\text { SE of } \\
\text { B }\end{array}$ & t(66) & $p$ \\
\hline $\begin{array}{l}\text { Age (years) } \\
\text { CKMB on } \\
\text { admission }\end{array}$ & 0.2782 & 0.1024 & 0.0098 & 0.0036 & 2.7165 & 0.0080 \\
$\begin{array}{l}\text { Glucose } \\
\text { level on }\end{array}$ & 0.0705 & 0.1045 & 0.0008 & 0.0012 & 0.6745 & 0.5018 \\
admission & & & & & & \\
(mg \%) & & & & & & \\
$\begin{array}{l}\text { Ejection } \\
\text { fraction of } \\
\text { left ventricle } \\
\text { (\%) }\end{array}$ & -0.2777 & 0.1023 & -0.0119 & 0.0044 & -2.7144 & 0.0081 \\
$\begin{array}{l}\text { Significant } \\
\text { Cx stenosis }\end{array}$ & 0.2148 & 0.0948 & 0.1747 & 0,0771 & 2.2654 & 0.0261 \\
\hline
\end{tabular}

$\overline{C K M B}$ creatine kinase-myocardial band, $C x$ circumflex artery, $S E$ standard error

sion analysis showed that independent risk factors for death during the follow-up were: age, ejection fraction and $\mathrm{Cx}$ narrowing (Table 4).

\section{Discussion}

The long-term prognosis in patients with STEMI still requires improvement in the future. Different scales and factors predicting hospital and late outcomes have already been created [5-8]. Most of the scales used in mortality prediction lack angiographic and procedural aspects $[9$, 10]. One of the factors influencing the long-term efficacy of percutaneous interventions is the type of stent used for the procedure. Despite previous apprehension concerning drug-eluting stents (DES), they have turned out to be safe and efficient, also in the treatment of patients with acute coronary syndromes [11]. DES have significantly limited restenosis, which potentially may improve the prognosis of patients; however, data concerning the influence of reste- 
nosis on the mortality are equivocal $[12,13]$. Nevertheless, it seems that the presence of coronary heart disease itself and its advancement are more important in the prognosis than the appearance of restenosis, which can be effectively treated today [13]. We did not evaluate the influence of the type of stent on mortality in our study. However, there were no differences concerning the prevalence of DES in the compared groups (Table 1).

It should be borne in mind that disease affecting different segments and arteries may lead to diverse outcomes. The location of a lesion in the LAD could be of key importance in the prognosis of patients with STEMI, due to the fact that the occlusion of the proximal LAD is related to more extensive heart muscle damage and therefore worse outcomes [10]. Nevertheless, the location of LAD occlusion did not present with differences in our analysis, which is also reflected in the lack of differentiation of the ejection fraction of the left ventricle, a direct exponent of the level of impairment of left ventricle. The $\mathrm{Cx}$ artery is the least frequent culprit vessel among patients treated invasively for STEMI [3]. Furthermore, patients with $\mathrm{Cx}$ occlusion are less likely to present ST-segment elevation, hence they remain underdiagnosed. Nevertheless, it has not been established if the outcome differs depending on whether the stenosis is in the Cx or RCA, in patients with anterior STEMI treated invasively. In the presented study, we found that patients with $\mathrm{Cx}$ narrowing present with worse outcomes. The explanation for such an observation has not been clearly defined. Patients with LAD narrowing usually have collateral circulation from the RCA artery. Thus, RCA narrowing in patients with anterior STEMI should lead to worse compensatory backflow to the occluded LAD, affecting the outcome more than $\mathrm{Cx}$ stenosis. Moreover, some studies suggested that $\mathrm{Cx}$-related STEMI is usually smaller compared with RCA-related STEMI [14]. Such an observation should not be referred to the general population of patients with STEMI until coronary artery dominance is taken into consideration. Veltman et al. [15] reported that the prognosis of STEMI patients during a 30-day follow-up is worse in the case of left coronary artery dominance. According to the cited observation, discrepancies in the prognosis may result from the dominance of one artery and not directly from the type of the artery$\mathrm{Cx}$ or RCA. In the presented study, the prevalence of right dominance was similar in the two groups, hence it may not constitute an explanation for the differences in mortality. On the other hand, the differences in mortality may stem from the fact that $\mathrm{Cx}$ stenosis in patients with anterior STEMI can be interpreted as an equivalent of left main disease, leading to worse outcome. Nevertheless, all the patients in our study underwent staged PCI procedures and were fully revascularised. This is of key importance taking into consideration the debate on the justification of complete revascularisation in STEMI. The latest publications have shown that patients who underwent complete coronary revascularisation in the acute phase of STEMI have a better prognosis than the others $[16,17]$. These studies raise controversies, mainly due to the fact that the results are inconsistent with the results of large trials and meta-analyses [18-21]. Newly presented and vastly discussed trials seem to only support the justification of complete revascularisation in patients with myocardial infarction regarding the aspect of the improvement of the prognosis. However, they do not report the optimal time of complete revascularisation. Undoubtedly, we will be provided with more information from large randomised ongoing trials, e.g. the COMPLETE study. In the presented study, staged revascularisation was performed during a period of 1 month in all the subjects. Consequently, it should not affect the differences in mortality between the groups. Regardless of such treatment, the prognosis of patients with $\mathrm{Cx}$ stenosis was worse. Poor outcomes of the $\mathrm{Cx}$ group of patients may finally result from missing ECG changes at the time of $\mathrm{Cx}$ reocclusion during the observation. This suggests that the 12-lead ECG alone is often not enough for the diagnosis of patients with suspected $\mathrm{Cx}$ occlusion or narrowing. According to the authors, this may stem from the fact that electrocardiographically asymptomatic $\mathrm{Cx}$ reocclusion during the follow-up could be more common than in the case of RCA. The issue refers to long-term follow-up and not only to the anterior infarction-related period. This may result from atherosclerosis progression, acceleration of the narrowing in already diseased vessels and finally myocardial ischaemia. Additionally, it may be caused by acute occlusion related to the atherosclerotic plaque rupture in that artery. However, these are only unconfirmed assumptions. Therefore, we should be aware of features of Cx occlusion other than STsegment elevation, such as isolated ST-segment depression in precordial leads (the greatest in leads V2 and V3) [22]. According to our findings, patients with anterior STEMI and $\mathrm{Cx}$ stenosis represent a group that requires a thorough evaluation during the follow-up period. $\mathrm{Cx}$ is a coronary artery requiring special attention because its stenosis in patients with anterior STEMI treated with PCI of the LAD leads to a worse prognosis in comparison with patients with RCA narrowing.

This study has a few limitations. First is the relatively small number of patients. However, to achieve a homogenous group of patients, we studied 3121 consecutive patients with STEMI. The observed correlation could be confirmed in the future with prospective and larger population studies. Moreover, we used overall mortality as an endpoint, due to the fact that it was not possible to define the cause of death in all cases. Thus, we are not certain whether all reported deaths were cardiovascular. Concluding, significant narrowing of the $\mathrm{Cx}$ leads to worse outcomes than narrowing of the RCA in patients with STEMI treated with PCI of the LAD. Thus, patients with $\mathrm{Cx}$ narrowing should be treated 
more cautiously and require special attention after anterior STEMI treated with PCI of LAD.

Funding This work was supported by grants 144-81532L and 13381881L from Medical University of Bialystok.

\section{Conflict of interest None.}

Open Access This article is distributed under the terms of the Creative Commons Attribution License which permits any use, distribution, and reproduction in any medium, provided the original author(s) and the source are credited.

\section{References}

1. Kozuch M, Kralisz P, Korecki J, et al. Early and long-term prognosis of patients with coronary artery disease treated with percutaneous coronary interventions in 2005. Experience of single large-volume PCI centre. Adv Med Sci. 2011;56:222-30.

2. Berger PB, Ryan TJ. Inferior myocardial infarction. High-risk subgroups. Circulation. 1990;81:401-11.

3. From AM, Best PJ, Lennon RJ, Rihal CS, Prasad A. Acute myocardial infarction due to left circumflex artery occlusion and significance of ST-segment elevation. Am J Cardiol. 2010;106:1081-5.

4. Veltman CE, de Graaf FR, Schuijf JD, et al. Prognostic value of coronary vessel dominance in relation to significant coronary artery disease determined with non-invasive computed tomography coronary angiography. Eur Heart J. 2012;33:1367-77.

5. Tomaszuk-Kazberuk A, Kozuch M, Malyszko J, et al. Do overweight patients have a better five years prognosis after an acute myocardial infarction treated with coronary intervention? Kardiol Pol. 2012;70:686-93.

6. Tomaszuk-Kazberuk A, Kozuch M, Małyszko J, et al. What level of hyperglycaemia on admission indicates a poor prognosis in patients with myocardial infarction treated invasively? Kardiol Pol. 2012;70:564-72.

7. Tomaszuk-Kazberuk A, Kozuch M, Bachorzewska-Gajewska H, Malyszko J, Dobrzycki S, Musial WJ. Does lack of ST-segment resolution still have prognostic value 6 years after an acute myocardial infarction treated with coronary intervention? Can J Cardiol. 2011;27:573-80.

8. Kozuch M, Dobrzycki S, Nowak K, et al. Lack of ST-segment depression normalization after PCI is a predictor of 5-year mortality in patients with ST-elevation myocardial infarction. Circ J. 2007;71:1851-6.

9. Hamm CW, Bassand JP, Agewall S, et al. ESC Guidelines for the management of acute coronary syndromes in patients presenting without persistent ST-segment elevation. Eur Heart J. 2011;32:2999-3054.
10. Steg PG, James SK, Atar D, et al. ESC Guidelines for the management of acute myocardial infarction in patients presenting with ST-segment elevation. Eur Heart J. 2012;33:2569-619.

11. Velders MA, van Boven AJ, Brouwer J, et al. Everolimus- and sirolimus-eluting stents in patients with and without ST-segment elevation myocardial infarction. Neth Heart J. 2014;22:167-73.

12. Espinola-Klein C, Rupprecht HJ, Erbel R, et al. Impact of restenosis 10 years after coronary angioplasty. Eur Heart $\mathrm{J}$. 1998;19:1047-53.

13. Verschuren JJ, Trompet S, Tio RA, de Winter RJ, Doevendans PA, Jukema JW. Ten-year mortality risk of patients undergoing elective PCI: long-term follow-up of the GENetic Determinants of Restenosis (GENDER) study: no increased mortality risk by restenosis, only by coronary artery disease itself. Neth Heart J. 2013;21:101-5.

14. Kim SS, Choi HS, Jeong MH, et al. Clinical outcomes of acute myocardial infarction with occluded left circumflex artery. J Cardiol. 2011;57:290-6.

15. Veltman CE, van der Hoeven BL, Hoogslag GE, et al. Influence of coronary vessel dominance on short-and long-term outcome in patients after ST-segment elevation myocardial infarction. Eur Heart J. 2014; doi:10.1093/eurheartj/ehu236.

16. Wald DS, Morris JK, Wald NJ, et al. Randomized trial of preventive angioplasty in myocardial infarction. $\mathrm{N}$ Engl $\mathrm{J}$ Med. 2013;369:1115-23.

17. Gershlick AH. Complete versus Lesion only PRimary-PCI Trial (CvLPRIT): treat the infarct-related artery only or all lesions? Presented at: European Society of Cardiology Congress. Spain: Barcelona; 2014. (Unpublished results).

18. Kornowski R, Mehran R, Dangas G, et al. Prognostic impact of staged vs. "one-time" multivessel percutaneous intervention in acute myocardial infarction: analysis from the HORIZONS-AMI trial. J Am Coll Cardiol. 2011;58:704-11.

19. Hannan EL, Samadashvili Z, Walford G, et al. Culprit vessel percutaneous coronary intervention vs. multivessel and staged percutaneous coronary intervention for ST-segment elevation myocardial infarction patients with multivessel disease. JACC Cardiovasc Interv. 2010;3:22-31.

20. Toma M, Buller CE, Westerhout CM, et al. Non-culprit coronary artery percutaneous coronary intervention during acute ST-segment elevation myocardial infarction: insights from the APEXAMI trial. Eur Heart J. 2010;31:1701-7.

21. Vlaar PJ, Mahmoud KD, Holmes DR Jr, et al. Culprit vessel only vs. multivessel and staged percutaneous coronary intervention for multivessel disease in patients presenting with ST-segment elevation myocardial infarction: a pairwise and network meta-analysis. J Am Coll Cardiol. 2011;58:692-703.

22. Shah A, Wagner GS, Green CL, et al. Electrocardiographic differentiation of the ST-segment depression of acute myocardial injury due to the left circumflex artery occlusion from that of myocardial ischemia of nonocclusive etiologies. Am J Cardiol. 1997;80:512-3. 